\title{
The opinion of French pulmonologists and palliative care physicians on non-invasive ventilation during palliative sedation at end of life: a nationwide survey
}

\author{
V. Guastella ${ }^{*}$, G. Piwko², A. Greil ${ }^{2}$, C. Lambert ${ }^{3}$ and A. Lautrette ${ }^{4}$
}

\begin{abstract}
Background: Deciding to withdraw non-invasive ventilation (NIV) at end-of-life (EOL) in patients with chronic respiratory failure is a challenge. The European Association for Palliative Care recommends not maintaining artificial therapies that could prolong life during palliative sedation (PS) at EOL. The aim of this survey was to assess palliative care physicians' and pulmonologists' opinion on withdrawing or maintaining NIV in patients with chronic respiratory failure during PS at EOL.

Methods: From April to May 2019, we performed a prospective survey among pulmonologists $(n=1545)$ and palliative care physicians $(n=631)$ in France to determine the prevalence of opinion in favour of maintaining NIV and identify the factors associated with opinion in favour of withdrawing or maintaining NIV with multiple logistic regression.

Results: A total of 457 participants were enrolled comprising 202 pulmonologists and 255 palliative care physicians. An opinion in favour of maintaining NIV was found in 88 (19.3 95\% Cl [15.7; 23.2]) physicians comprising 57 (28.2\%) pulmonologists and $31(12.2 \%)$ palliative care physicians $(p<0.001)$. The factors associated with an opinion in favour of maintaining NIV were spending time looking for advanced directives (AD) in the patient's file (odds ratio (OR): $6.54,95 \% \mathrm{Cl}[2.00 ; 21.32], p=0.002)$ and personal ethics of physicians (OR: 17.97, 95\% Cl [9.52; 33.89], $p<0.001)$. The factor associated with an opinion in favour of withdrawing NIV was palliative care training (OR: $0.31,95 \% \mathrm{Cl}[0.16$; $0.60], p<0.001)$. The three main reasons in favour of maintaining NIV among the nine identified were emotional comfort for close relatives, reducing discomfort of dyspneoa and anticipation of suffocation.

Conclusion: In France, around 20\% of pulmonologists and palliative care physicians declared an opinion in favour of maintaining NIV during PS at EOL because of their personal ethics and spending time looking for AD, if any, in the patient's file. Palliative care training can stimulate reflection help foster a change of opinion about practices, especially in the case of patients with NIV during PS at EOL.
\end{abstract}

Keywords: Palliative care, End of life, Non-invasive ventilation, Limitation of treatment

\footnotetext{
*Correspondence: vguastella@chu-clermontferrand.fr

'Palliative Care Unit, Montpied Hospital, University Hospital of

Clermont-Ferrand, 54 rue Montalembert, BP69, 63003 Clermont-Ferrand, Cedex 1, France

Full list of author information is available at the end of the article
}

(c) The Author(s). 2021 Open Access This article is licensed under a Creative Commons Attribution 4.0 International License, which permits use, sharing, adaptation, distribution and reproduction in any medium or format, as long as you give appropriate credit to the original author(s) and the source, provide a link to the Creative Commons licence, and indicate if changes were made. The images or other third party material in this article are included in the article's Creative Commons licence, unless indicated otherwise in a credit line to the material. If material is not included in the article's Creative Commons licence and your intended use is not permitted by statutory regulation or exceeds the permitted use, you will need to obtain permission directly from the copyright holder. To view a copy of this licence, visit http://creativecommons.org/licenses/by/4.0/ The Creative Commons Public Domain Dedication waiver (http://creativecommons.org/publicdomain/zero/1.0/) applies to the data made available in this article, unless otherwise stated in a credit line to the data. 


\section{Background}

The aim of palliative care is retaining comfort until death without unreasonable obstinacy in patients with a severe critical illness in an end-of-life (EOL) setting. Whenever life-sustaining therapies are unable to improve a patient's outcome, or paradoxically may prove more burdensome than beneficial, physicians must decide whether to withdraw or maintain therapies. The decision-making process during palliative sedation (PS) at EOL is standardized in the guidelines of the European Association for Palliative Care (EAPC), and favours not maintaining sustaining treatments when they prolong dying without improving the comfort of a patient with no hope of recovery [1-4]. Non-invasive ventilation (NIV) is a sustaining respiratory assistance in patients with chronic respiratory failure. Its use has greatly increased in the last few years [5] because it improves both prognosis and the quality of life and sleep [6]. At EOL, invasive therapies should be stopped because the main goal is then to enhance comfort. Dyspnoea is a frequent symptom in palliative situations with multifactorial aetiologies and a complex mechanism. In this context, therapies to alleviate dyspnoea show limited effectiveness. Finally, physicians are faced with refractory symptoms leading to asphyxia. NIV can alleviate symptoms [7, 8]. Some authors report that NIV improve the symptoms of acute respiratory failure in patients with contraindications for more invasive procedures such as orotracheal intubation $[9,10]$, It reduces the subjective sensation of dyspnoea by lessening respiratory muscular work [11] Some others consider that maintaining NIV in a failing clinical condition may prolong dying unnecessarily [12]. Some patients describe NIV as an unpleasant therapy [13]. There is thus a choice between enhancing comfort by withdrawing or by maintaining NIV (as a way to relieve dyspnoea) [14].

In France, two laws, Leonetti 2005 [15] and Claeys Leonetti 2016 [14] regulate the procedures for withholding and withdrawing life-sustaining treatment at EOL. These laws proscribe unreasonable obstinacy. Some physicians may view the use of NIV at EOL as unreasonable obstinacy. A patient with chronic respiratory failure requiring NIV at EOL is managed by pulmonologists or palliative care physicians. The main difference between the two specialists is the timing in the care pathway. The palliative care physicians take care of patients at EOL. The pulmonologists take care of them from the onset of their respiratory disease and chronically. The follow-up by the pulmonologists is longer [13, 15]. At EOL, only one physician (pulmonologist or palliative care physician) takes care of the patient and communicates with the family.

The aim of this survey was to determine the prevalence of opinion in favour of maintaining NIV during PS at EOL among pulmonologists and palliative care physicians, who are the physicians taking care of patients with chronic respiratory failure. The secondary objective was to determine the factors associated with an opinion in favour of withdrawing or maintaining NIV.

\section{Methods}

We conducted a prospective survey from April to May 2019 in all French pulmonologists $(n=1545)$ belonging to the French Pulmonology Society, and palliative care physicians $(n=631)$ belonging to the French Palliative Care Society. There were no exclusion criteria. This survey involving human participants, was performed in compliance with the Declaration of Helsinki and was approved by an ethics committee: Comité de Protection des Personnes SUD EST VI (No. IRB 00008526, reference: 2020 / CE 77). An informed consent to participate in this survey was obtained from all the participants. The physicians were contacted by e-mail for enrollment and completed an attached questionnaire. The questionnaire was created by a multidisciplinary team made up of two pulmonologists and two palliative care physicians who were volunteered to participate in the survey including one professor and one physician at the end of their career, one physician in the middle of their career and one physician at the start of their career. The questionnaire was based on their own experience during brainstorming because no literature dealt with this subject.

Every participant completed an anonymous questionnaire (Supplementary File 1) including the physicians' characteristics: gender, age, professional status, specific training in palliative care and/or NIV, at least one previous experience with the situation of EOL, unease in deciding to withdraw NIV, personal ethics in favour of maintaining NIV, and spending time looking for advanced directives (AD). Physicians were then asked whether their opinion was in favour of withdrawing or maintaining NIV during PS at EOL. The physicians with an opinion in favour of maintaining NIV were asked to state their reasons.

\section{Statistical analysis}

The initial hypothesis was that $10-15 \%$ of physicians maintained NIV, determined with personal data, obtained from a survey, carried out by doctors $(n=20)$, on a given day, in our University Hospital.

Thus for a proportion of $15 \%$ (requiring the most subjects), 196 subjects would provide an accuracy of $\pm 5 \%$, and 307 subjects an accuracy of $\pm 4 \%$.

Statistical analysis was performed using Stata software (version 15; StataCorp, College Station, Texas, USA). All tests were two-sided, with a Type I error set at 0.05. All data were expressed as frequencies and associated 
percentages, except for the physicians' age expressed as mean \pm standard deviation. The number of physicians whose opinion was in favour of maintaining NIV was expressed as a rate with a $95 \%$ confidence interval (CI). Factors associated with maintaining NIV were studied using the chi-squared test or Fisher's exact test for categorical variables, and Student's $t$-test for quantitative ones (physicians' age). A multivariate analysis was carried out using a logistic regression, considering the covariates according to univariate results and clinical relevance: training in palliative care, training in NIV, looking for $\mathrm{AD}$, and personal ethics in support of maintaining NIV. The results were expressed as odds ratio (OR) and 95\% CI. Comparisons according to the physicians' speciality were made as described previously.

\section{Results}

A total of 457 physicians were enrolled in the survey population, comprising 202 pulmonologists, representing 13.1\% of all French pulmonologists, and 255 palliative care physicians, representing $40.4 \%$ of all French palliative care physicians (Fig. 1).

The overall prevalence of opinion in favour of maintaining NIV during PS at EOL was $19.3 \%$ in the survey population. The characteristics of physicians are shown in Table 1. The prevalence of opinion in favour of maintaining NIV during PS among the pulmonologists was significantly higher than among the palliative care physicians $(28.2 \%$ vs. $12.2 \%$ respectively, $p<0.001)$.

In univariate analysis (Table 2), the opinion in favour of maintaining NIV was associated with the pulmonology speciality, training NIV, unease in deciding to withdraw NIV after an experience in PS at EOL, personal ethics in support of maintaining NIV and the spending time looking for any AD in the patient's file.

In the multivariable analysis, the factors associated with an opinion in favour of maintaining NIV were the spending time looking for any $\mathrm{AD}$ in the patient's file and personal ethics physicians. The factor associated with an opinion in favour of withdrawing NIV was palliative care training. The training in NIV was not associated with an opinion in favour of withdrawing or maintaining NIV (Table 3).

Nine reasons in favour of maintaining NIV were identified among the 88 physicians with this opinion (Fig. 2). The three most prevalent reasons were emotional comfort for close relatives, reducing discomfort of dyspnoea, and anticipation of suffocation.

\section{Discussion}

This survey performed in France shows that 20\% of the practitioners still had favourable opinion of maintaining NIV during PS at EOL. Palliative care training was a factor associated with opinion in favour of withdrawing NIV in contrast to the

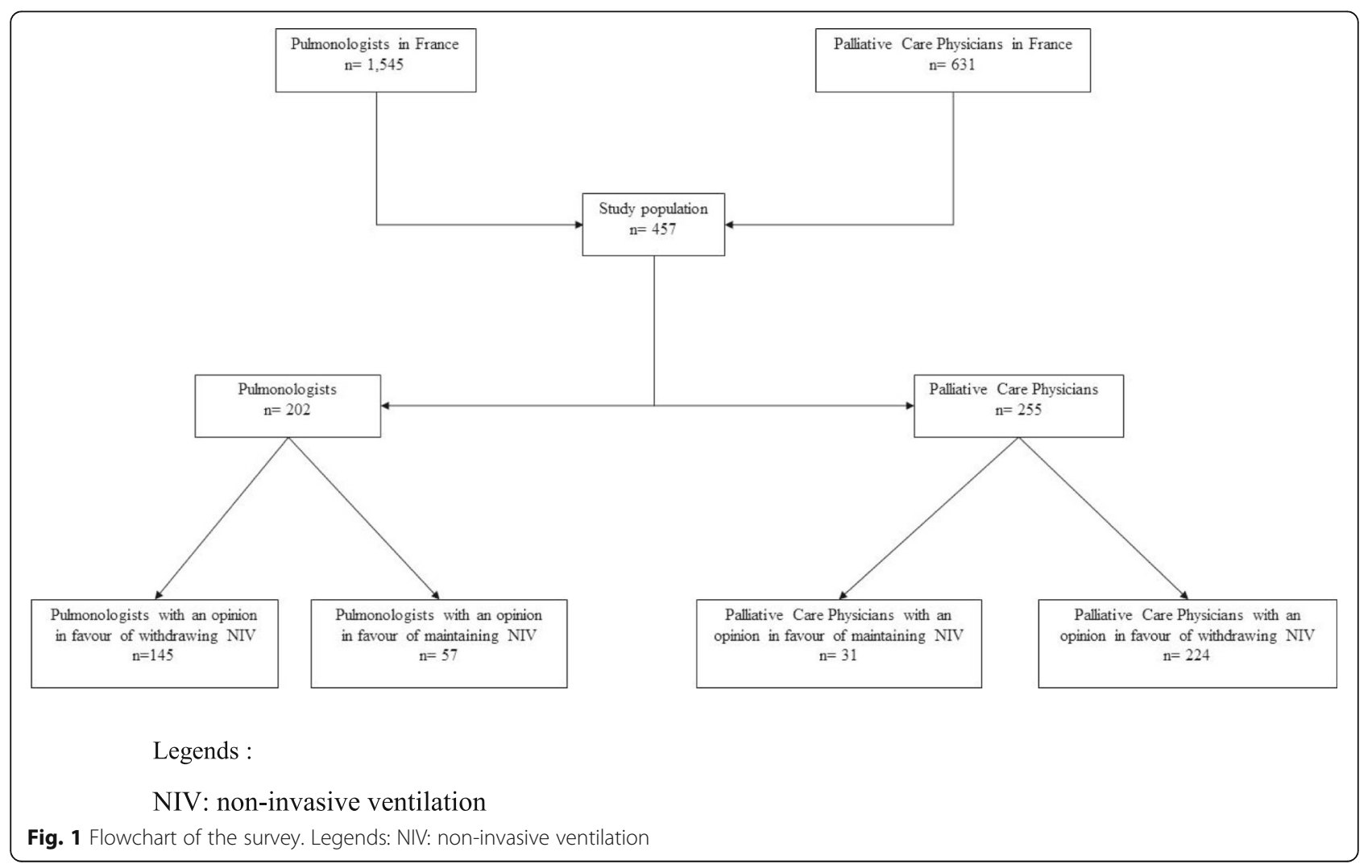


Table 1 Pulmonologists' and palliative care physicians' characteristics

\begin{tabular}{|c|c|c|c|c|}
\hline & $\begin{array}{l}\text { Study population } \\
(n=457)\end{array}$ & $\begin{array}{l}\text { Pulmonologists } \\
(n=202)\end{array}$ & $\begin{array}{l}\text { Palliative care physicians } \\
(n=255)\end{array}$ & $p$ \\
\hline Female gender & $256(56.0)$ & $102(50.5)$ & $154(60.4)$ & 0.034 \\
\hline Age (years) & $45.6 \pm 12.1$ & $44.3 \pm 12.3$ & $46.6 \pm 11.8$ & 0.040 \\
\hline \multicolumn{5}{|l|}{ Status of physicians } \\
\hline Senior practitioner & $437(95.6)$ & $188(93.1)$ & $249(97.6)$ & 0.018 \\
\hline Professor & $20(4.4)$ & $14(6.9)$ & $6(2.4)$ & \\
\hline Training in palliative care & $284(62.1)$ & $29(14.4)$ & $255(100.0)$ & $<0.001$ \\
\hline Training in NIV & $161(35.2)$ & $138(68.3)$ & $23(9.0)$ & $<0.001$ \\
\hline Training in NIV and palliative care & $44(9.6)$ & $21(10.4)$ & $23(9.0)$ & 0.62 \\
\hline Opinion in favour of maintaining NIV & $88(19.3)$ & $57(28.2)$ & $31(12.2)$ & $<0.001$ \\
\hline Experience of NIV use at EOL with palliative sedation & $277(60.6)$ & $133(65.8)$ & $144(56.5)$ & 0.042 \\
\hline Doctor uneasy in deciding to withdraw NIV & $145 / 277(52.3)$ & $88 / 133(66.2)$ & $57 / 144(39.6)$ & $<0.001$ \\
\hline Personal ethics support maintaining NIV & $71(15.5)$ & $39(19.3)$ & $32(12.5)$ & 0.048 \\
\hline Spending time looking for AD in the patient's file & $394(86.2)$ & $161(79.7)$ & $233(91.4)$ & $<0.001$ \\
\hline
\end{tabular}

Data are presented as frequencies (associated percentages), or mean \pm standard deviation

$E O L$ end of life, NIV noninvasive ventilation, $A D$ advanced directives

research time for $\mathrm{AD}$. Spending time looking for any $\mathrm{AD}$ in the patient's file and personal ethics of physicians were associated with the opinion in favour of maintaining NIV during PS at EOL $[16,17]$. Most often, patients' preferences were unknown, and so decisions remained primarily based on medical judgment [18]. The consensus was that lifesustaining treatments should be maintained or withdrawn when they prolong dying without improving the comfort of a patient with no hope of recovery. Guidelines state that the same professional ethics apply to maintaining and to withdrawing life support $[17,18]$. The decision-making process for treatment limitations is standardized in guidelines, although everyday practice is characterized by some variability related to social and religious factors, and the personal ethics of physicians, staff members, patients, and relatives $[19,20]$. The French Claeys Leonetti law on the end of life (February

Table 2 Differences in characteristics between physicians with an opinion in favour of maintaining NIV and physicians with an opinion in favour of withdrawing NIV

\begin{tabular}{|c|c|c|c|}
\hline & Withdrawing $(n=369)$ & Maintaining $(n=88)$ & $p$ \\
\hline Female gender & $202(54.7)$ & $54(61.4)$ & 0.26 \\
\hline Age (years) & $45.7 \pm 12.1$ & $45.0 \pm 12.2$ & 0.64 \\
\hline \multicolumn{4}{|l|}{ Status of physicians, } \\
\hline Senior practitioner & $351(95.1)$ & $86(97.7)$ & \multirow[t]{2}{*}{0.39} \\
\hline Professor & $18(4.9)$ & $2(2.3)$ & \\
\hline \multicolumn{4}{|l|}{ Speciality of physicians } \\
\hline Pulmonologists & $145(39.3)$ & $57(64.8)$ & \multirow[t]{2}{*}{$<0.001$} \\
\hline Palliative care physicians & $224(60.7)$ & $31(35.2)$ & \\
\hline Training in palliative care & $245(66.4)$ & $39(44.3)$ & $<0.001$ \\
\hline Training in NIV & $122(33.1)$ & $39(44.3)$ & 0.047 \\
\hline Training in NIV and palliative care & $37(10.0)$ & $7(8.0)$ & 0.55 \\
\hline Experience of NIV use at EOL with palliative sedation & $217(58.8)$ & $60(68.2)$ & 0.11 \\
\hline Doctor uneasy in deciding to withdraw NIV & $105 / 217(48.4)$ & $40 / 60(66.7)$ & 0.012 \\
\hline Personal ethics support maintaining NIV & $24(6.5)$ & $47(53.4)$ & $<0.001$ \\
\hline Spending time looking for $A D$ in the patient's file & $310(84.0)$ & $84(95.4)$ & 0.005 \\
\hline
\end{tabular}

Data are presented as frequencies (associated percentages), or mean \pm standard deviation. $E O L$ end of life, NIV non-invasive ventilation, $A D$ advanced directives 
Table 3 Multivariable analysis of the factors associated with an opinion in favour of maintaining non-invasive ventilation

\begin{tabular}{lll}
\hline & OR [95\% Cl] & $\boldsymbol{p}$ \\
\hline Training in palliative care & $0.31[0.16 ; 0.60]$ & $<0.001$ \\
Training in NIV & $0.83[0.43 ; 1.61]$ & 0.58 \\
Spending time looking for any AD in the patient's file & $6.54[2.00 ; 21.32]$ & 0.002 \\
Personal ethics support maintaining NIV & $17.97[9.52 ; 33.89]$ & $<0.001$ \\
\hline
\end{tabular}

$A D$ advanced directives, $C l$ confidence interval, NIV non-invasive ventilation, $O R$ odds ratio

2, 2016) [14] entitles patients to ask for PS at EOL that induces decreased the awareness until death. This is put in place after a common decision in the case of a serious, incurable affection that is life-threatening in the short term.

Given the 20\% rate of maintaining NIV found among doctors surveyed in this study, the important question that arises is why this rate is still so high when the law proscribes stubborn life support in this situation and how it can be lowered. We see that decisions and attitudes are dictated by the doctors' personal ethics concerning the NIV without training in NIV and in palliative care. Doctors with training in palliative care are less likely to maintain NIV than those without. They are more aware of guidelines, and being trained they feel

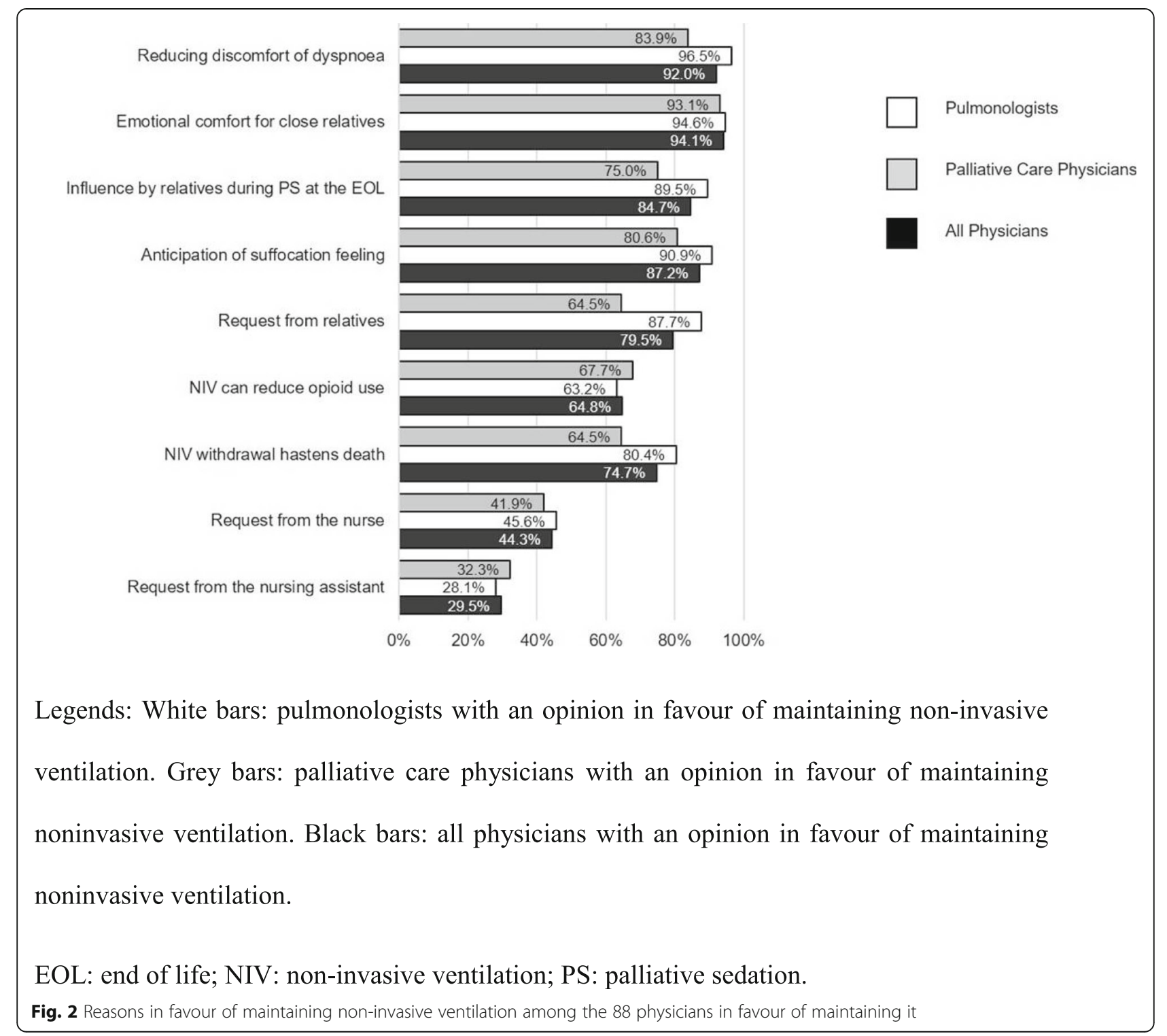


better able to make reasoned decisions in these types of medical situation. Pulmonologists are trained in NIV and know the benefits of this technical innovation and particularly the symptomatic comfort it brings to patients, and so are reluctant to withdraw it. Their behaviour is also different from that of palliative care physicians because they are so used to seeing their patients with NIV as a life support. NIV is an efficient chronic therapy for pulmonologists and they can minimize the discomfort related to NIV [21-23]. By contrast, the palliative care physicians prioritize comfort at EOL over respiratory therapy. The stage of patient care for pulmonologists and palliative care physicians is different, so the perception of therapy support with NIV by the two specialities may also be different. For the palliative care physicians, the NIV can be perceived as a cause of discomfort, whereas it remains a vital therapy for the pulmonologists. In our study, spending time looking for any $\mathrm{AD}$ in the patient's file was identified as a factor associated with an opinion in favour of maintaining NIV. Further looking for AD into the patient's file will enable to figure out the latter's will. It is possible that the physicians with an opinion in favour of maintaining NIV want to validate their decision with the $A D$ because they know that their opinion is in the minority.

There is also a significant influence of the family on doctors. Whereas caregivers undergo no such influence. Information about sustaining treatment and sedation practices should be given to every citizen because anyone can be faced with a similar situation. In this way, EOL could be better anticipated, rather than having to decide each time an acute situation arises.

\section{Limitations and strengths of the study}

A binary question such as withdrawing or maintaining NIV during PS without any context except for the EOL is admittedly hard to answer. It requires ethical reflection, and it omits many important questions in regard to PS at EOL. The lack of context and the binary response design may thus skew the survey results.

Finally, we cannot claim that the survey sample is fully representative of all the French physicians caring for patients with NIV for chronic respiratory failure at EOL as this was an observational study.

A strength of the survey is that the professionals surveyed had very different training on the same practice during PS at EOL. This survey yielded up-to-date, detailed data on maintaining or withdrawing NIV, so opening numerous perspectives for research.

This survey is an opinion poll. It would be of interest to perform a prospective survey and study what really happens at the patients' bedside. It is always difficult for a practitioner to take part in an opinion survey outside a real clinical situation.

\section{Conclusion}

To sum up, our survey shows that in most cases, physicians had an opinion in favour of withdrawing NIV, but $20 \%$ still had a favourable opinion of maintaining it. We also found that palliative care training was a factor associated with an opinion in favour of withdrawing NIV, whereas spending time looking for any $\mathrm{AD}$ in the patient's file and physicians' personal ethics were associated with an opinion in favour of maintaining NIV. Scientific and technical skills are needed for proper care techniques, but so also are interpersonal, ethical, legal and reflexive skills.

\section{Abbreviations}

EOL: End of life; AD: Advanced directives; PS: Palliative sedation; NIV: Noninvasive ventilation

\section{Supplementary Information}

The online version contains supplementary material available at https://doi. org/10.1186/s12904-021-00755-w.

\section{Additional file 1.}

\section{Acknowledgements}

The authors thank Bertrand Degre and Ryan Richard for editing the manuscript.

\section{Authors' contributions \\ G.P. and V.G. conceived and designed the survey; G.P. collected the data; V.G., G.P., A.G., C.L. and A.L. analysed and interpreted data; V.G., C.L. and A.L. drafted the report. All authors contributed to the manuscript review and approved the final version.}

Funding

This survey did not receive any funding.

Availability of data and materials

The data that support the findings of this survey are available from the corresponding author upon reasonable request.

\section{Declarations}

Ethics approval and consent to participate

This study involving human participants was performed in compliance with the Declaration of Helsinki and was approved by an ethics committee: Comité de Protection des Personnes SUD EST VI (No. IRB 00008526, reference: 2020 / CE 77). Informed consent to participate in this survey was obtained from all participants.

Consent for publication

Not applicable.

\section{Competing interests}

Authors do not have any conflict of interest

\section{Author details}

${ }^{1}$ Palliative Care Unit, Montpied Hospital, University Hospital of Clermont-Ferrand, 54 rue Montalembert, BP69, 63003 Clermont-Ferrand, Cedex 1, France. ${ }^{2}$ Pulmonology Unit, Montpied Hospital, University Hospital of Clermont-Ferrand, Clermont-Ferrand, France. ${ }^{3}$ Biostatistics unit (DRCI), Montpied Hospital, University Hospital of Clermont-Ferrand, Clermont-Ferrand, France. ${ }^{4}$ Medical Intensive Care, Montpied Hospital, University Hospital of Clermont-Ferrand, Clermont-Ferrand, France. 
Received: 18 December 2020 Accepted: 15 March 2021

Published online: 17 May 2021

\section{References}

1. Cherny NI. ESMO Clinical Practice Guidelines for the management of refractory symptoms at the end of life and the use of palliative sedation. Ann Oncol. 2014;25:iii143-52.

2. Cherny NI, Radbruch L, Board of the European Association for Palliative Care. European Association for Palliative Care (EAPC) recommended framework for the use of sedation in palliative care. Palliat Med. 2009;23: 581-93.

3. Cherny NI, Portenoy RK. Sedation in the management of refractory symptoms: guidelines for evaluation and treatment. J Palliat Care. 1994; 10(2):31-8. https://doi.org/10.1177/082585979401000207.

4. Cunningham J. A review of sedation for intractable distress in the dying. Ir Med J. 2008;101(3):87-90.

5. Demoule A, Girou E, Richard J-C, Taillé S, Brochard L. Increased use of noninvasive ventilation in French intensive care units. Intensive Care Med. 2006;32(11):1747-55. https://doi.org/10.1007/s00134-006-0229-z.

6. Bourke SC, Tomlinson M, Williams TL, Bullock RE, Shaw PJ, Gibson GJ. Effects of non-invasive ventilation on survival and quality of life in patients with amyotrophic lateral sclerosis: a randomised controlled trial. Lancet Neurol. 2006;5(2):140-7. https://doi.org/10.1016/S1474-4422(05)70326-4.

7. Clini E, Sturani C, Rossi A, Viaggi S, Corrado A, Donner CF, et al. The Italian multicentre study on noninvasive ventilation in chronic obstructive pulmonary disease patients. Eur Respir J. 2002;20(3):529-38. https://doi.org/1 0.1183/09031936.02.02162001.

8. Curtis JR, Cook DJ, Sinuff T, White DB, Hill N, Keenan SP, et al. Noninvasive positive pressure ventilation in critical and palliative care settings: understanding the goals of therapy. Crit Care Med. 2007;35(3):932-9. https:// doi.org/10.1097/01.CCM.0000256725.73993.74.

9. Carlucci A, Guerrieri A, Nava S. Palliative care in COPD patients: is it only an end-of-life issue? Eur Respir Rev Off J Eur Respir Soc. 2012:21(126):347-54. https://doi.org/10.1183/09059180.00001512.

10. Freichels TA. Palliative ventilatory support: use of noninvasive positive pressure ventilation in terminal respiratory insufficiency. Am J Crit Care Off Publ Am Assoc Crit-Care Nurses. 1994;3:6-10.

11. Levy M, Tanios MA, Nelson D, Short K, Senechia A, Vespia J, et al. Outcomes of patients with do-not-intubate orders treated with noninvasive ventilation*. Crit Care Med. 2004;32(10):2002-7. https://doi.org/10.1097/01. CCM.0000142729.07050.C9.

12. Tripodoro VA, Rabec CA, De Vito EL. Withdrawing noninvasive ventilation at end-of-life care: is there a right time? Curr Opin Support Palliat Care. 2019; 13(4):344-50. https://doi.org/10.1097/SPC.0000000000000471.

13. Beckert $L$, Wiseman $R$, Pitama $S$, Landers $A$. What can we learn from patients to improve their non-invasive ventilation experience? 'It was unpleasant; if I was offered it again, I would do what I was told'. BMJ Support Palliat Care. 2020;10(1):e7. https://doi.org/10.1136/bmispcare-2016-001151.

14. LOI n²016-87 du 2 février 2016 créant de nouveaux droits en faveur des malades et des personnes en fin de vie (1). 2016

15. LOI n²005-370 du 22 avril 2005 relative aux droits des malades et à la fin de vie - Dossiers législatifs - Légifrance. https://www.legifrance.gouv.fr/ dossierlegislatif/JORFDOLE000017758874/. Accessed 3 Feb 2021.

16. Sprung $\mathrm{CL}$, Maia $\mathrm{P}$, Bulow H-H, Ricou B, Armaganidis A, Baras M, et al. The importance of religious affiliation and culture on end-of-life decisions in European intensive care units. Intensive Care Med. 2007:33(10):1732-9. https://doi.org/10.1007/s00134-007-0693-0.

17. Mark NM, Rayner SG, Lee NJ, Curtis JR. Global variability in withholding and withdrawal of life-sustaining treatment in the intensive care unit: a systematic review. Intensive Care Med. 2015;41(9):1572-85. https://doi.org/1 0.1007/s00134-015-3810-5

18. Lesieur O, Leloup M, Gonzalez F, Mamzer M-F. Withholding or withdrawal of treatment under French rules: a study performed in 43 intensive care units. Ann Intensive Care. 2015;5(1):56. https://doi.org/10.1186/s13613-015-0056-x.

19. Société de réanimation de langue. Limitation et arrêt des traitements en réanimation adulte. Actualisation des recommandations de la Société de réanimation de langue française. Réanimation. 2010;19:679-98.

20. Truog RD, Campbell ML, Curtis JR, Haas CE, Luce JM, Rubenfeld GD, et al. Recommendations for end-of-life care in the intensive care unit: a consensus statement by the American college [corrected] of critical care medicine. Crit Care Med. 2008;36(3):953-63. https://doi.org/10.1097/CCM. OB013E3181659096.

21. Ergan B, Oczkowski S, Rochwerg B, Carlucci A, Chatwin M, Clini E, et al. European Respiratory Society guidelines on long-term home non-invasive ventilation for management of COPD. Eur Respir J. 2019;54(3):1901003. https://doi.org/10.1183/13993003.01003-2019.

22. Meduri GU, Fox RC, Abou-Shala N, Leeper KV, Wunderink RG. Noninvasive mechanical ventilation via face mask in patients with acute respiratory failure who refused endotracheal intubation. Crit Care Med. 1994;22(10): 1584-90. https://doi.org/10.1097/00003246-199422100-00013.

23. Sprung $\mathrm{CL}$, Cohen SL, Sjokvist $\mathrm{P}$, Baras M, Bulow H-H, Hovilehto S, et al. End of-life practices in European intensive care units: the Ethicus study. JAMA. 2003;290(6):790-7. https://doi.org/10.1001/jama.290.6.790.

\section{Publisher's Note}

Springer Nature remains neutral with regard to jurisdictional claims in published maps and institutional affiliations.
Ready to submit your research? Choose BMC and benefit from:

- fast, convenient online submission

- thorough peer review by experienced researchers in your field

- rapid publication on acceptance

- support for research data, including large and complex data types

- gold Open Access which fosters wider collaboration and increased citations

- maximum visibility for your research: over $100 \mathrm{M}$ website views per year

At BMC, research is always in progress.

Learn more biomedcentral.com/submissions 